\title{
Isotope fractionation of palladium in chemical exchange reaction
}

\author{
By T. Fujii ${ }^{1, *}$, F. Moynier ${ }^{2}$, A. Agranier ${ }^{3}$, E. Ponzevera ${ }^{4}$ and M. Abe \\ ${ }^{1}$ Research Reactor Institute, Kyoto University, 2-1010 Asashiro Nishi, Kumatori, Sennan Osaka 590-0494, Japan \\ 2 Department of Earth and Planetary Sciences and McDonnell Center for Space Sciences, Washington University in St. Louis, \\ Campus Box 1169, 1 Brookings Drive, Saint Louis, MO 63130-4862, USA \\ 3 Institut Universitaire Européen de la Mer, Domaines Océaniques, UMR 6538, IUEM, Place Nicolas Copernic, 29820 Plouzané, France \\ ${ }^{4}$ Laboratoire de Géochimie et Métallogénie, Département Géosciences Marines, IFREMER, Z.I. Pointe du diable, BP70-29280 Plouzané, France \\ 5 Department of Chemistry, Graduate School of Science and Engineering, Tokyo Metropolitan University, 1-1 Minami-Osawa, Hachioji-shi, \\ Tokyo 192-0397, Japan
}

(Received November 27, 2009; accepted in revised form November 11, 2010)

\section{Palladium / Isotope fractionation / Crown ether / Solvent extraction / Nuclear field shift / Ab initio calculation}

\begin{abstract}
Summary. Palladium isotopes were fractionated by the solvent extraction technique with a crown ether. After purification by ion-exchange chemistry, the isotopic ratios of ${ }^{105} \mathrm{Pd} /{ }^{106} \mathrm{Pd},{ }^{108} \mathrm{Pd} /{ }^{106} \mathrm{Pd}$, and ${ }^{110} \mathrm{Pd} /{ }^{106} \mathrm{Pd}$ were determined by multiple-collector inductively coupled plasma mass spectrometry. Isotope fractionations between the two phases were found to be larger than $0.1 \%$. The isotope fractionation of the odd atomic mass isotope $\left({ }^{105} \mathrm{Pd}\right)$ showed a deviation from that estimated from the even atomic mass isotopes $\left({ }^{106} \mathrm{Pd},{ }^{108} \mathrm{Pd}\right.$, and $\left.{ }^{110} \mathrm{Pd}\right)$. The mass-independent isotope fractionation found was attributable to the nuclear field shift effect. The quantum chemical calculations for the different Pd species supported the validity of the isotope fractionation factors obtained.
\end{abstract}

\section{Introduction}

The isotopic composition of an element changes via chemical exchange reactions. This is because the equilibrium constant of a chemical exchange reaction corresponding to an isotope is slightly different from one to another isotope. The effect called chemical isotope effect (or simply, isotope effect) has been widely known and the chemical exchange is an isotope separation method based on the isotope effect. For example, isotopes of light elements, C [1], N [2], and $\mathrm{S}$ [3], were successfully separated by the chemical exchange in Urey's pioneering work. Even for heavy elements like U, isotope enrichment by chemical exchange is feasible [4].

The classic theory of isotope effect has been established by Urey, Bigeleisen, and Mayer [5,6]. The intramolecular vibrational energies are different in isotopologues due to the difference in the nuclear mass of isotopes. The theory only predicts the mass-dependent isotope fractionation. Exceptions to the rule have been found since the 1980s. The mass-independent isotope fractionations observed possessed a similar profile of isotopic variation in their nuclear charge

\footnotetext{
*Author for correspondence (E-mail: tosiyuki@ rri.kyoto-u.ac.jp).
}

radius [7]. The conventional mass-dependent theory was reconsidered by one of the original authors [8]. The theory has been extended to include correction terms to account for nuclear properties, especially the nuclear size and shape $[8,9]$. The nuclear field shift effect, which results from the isotopic change in the nuclear size and shape, is recognized as the major origin of the mass-independent isotope fractionation in chemical exchange reactions [10]. In recent studies on geochemistry and environmental chemistry, the nuclear field shift effect attracts attention as a possible origin of isotopic anomalies found in nature [11-14]. The effect via chemical exchange reactions may have accompanied the formation of these samples. In this context, laboratory scale experiments with highly precise analytical methods are important to understand the mechanism of the nuclear field shift effect.

The nuclear field shift effect has been found in a platinum group element, $\mathrm{Ru}[12]$, and hence the isotope fractionation characteristics in the same group are of interest. The nuclear field shift effect of palladium is demonstrated in the present study. Palladium has six stable isotopes whose natural abundances are $1.02 \%\left({ }^{102} \mathrm{Pd}\right), 11.14 \%\left({ }^{104} \mathrm{Pd}\right), 22.33 \%\left({ }^{105} \mathrm{Pd}\right)$, $27.33 \%\left({ }^{106} \mathrm{Pd}\right), 26.46 \%\left({ }^{108} \mathrm{Pd}\right)$, and $11.72 \%\left({ }^{110} \mathrm{Pd}\right)$. The nuclear charge radii of even atomic mass isotopes show a linear increase with mass, while that of an odd atomic mass isotope ${ }^{105} \mathrm{Pd}$ show a deviation from the linear relation [15]. This suggests that a mass-independent isotope fractionation may be observed in ${ }^{105} \mathrm{Pd}$. The isotope fractionation studied was a two phase distribution of $\mathrm{Pd}$, in which an aqueous solution and an organic solution were used. A macrocyclic compound, dicyclohexano-18-crown-6 (DC18C6) known as crown ether, was selected as a complexation agent with $\mathrm{Pd}$. The isotope fractionation has been found in the solvent extraction of Ca by crown ethers [16] and this application was expanded to various elements $[10,17]$. The isotopic ratios of Pd were measured precisely by multiple-collector inductively coupled plasma mass spectrometry (MC-ICP-MS).

In order to check the validity of the isotope separation factor obtained, we performed the molecular orbital calculations for related Pd complexes. The isotope fractionation via intramolecular vibrations was estimated as the reduced partition function ratio (RPFR) of isotopologues. The contri- 
bution of the nuclear volume to the RPFR was also estimated by an ab initio method.

\section{Experimental}

Dicyclohexano-18-crown-6 (over 98\% purity) was a product of Sigma-Aldrich, Co., Inc. Palladium dissolved in 10\% $\mathrm{HCl}$ was a product from Spex Plasma Standard, lot\#4-141Pd with a purity $>99.9 \%$. Other chemicals were reagent grade. Using the standard solution and $\mathrm{HCl}, 0.1 \mathrm{~mol} \mathrm{dm}^{-3}$ (M) $\mathrm{Pd}(\mathrm{II})$ with various $[\mathrm{HCl}]$ was prepared. The organic phase was $0.1 \mathrm{M} \mathrm{DC18C6}$ in 1,2-dichloroethane. A $7 \mathrm{~cm}^{3}$ aqueous solution and a $7 \mathrm{~cm}^{3}$ organic solution were mixed in a glass vial with a stirrer bar, and the glass vial was sealed. The two phases were stirred by a magnetic stirrer for $30 \mathrm{~min}$. After the extraction equilibrium was attained, the two phases were separated by centrifugation. An aliquot of the upper aqueous solution was taken for analysis. These procedures were carried out at $298 \pm 0.5 \mathrm{~K}$. The Pd concentration in the back extraction water was analyzed by ICP-AES (Shimadzu, ICPS-100TR). The typical uncertainty of volumetric treatment was estimated to be $<5 \%$.

Organic impurities carried over the extraction were separated from $\mathrm{Pd}$ on anion exchange resin (AG1X8 200-400 mesh) in $\mathrm{HBr} / \mathrm{HNO}_{3}$. The sample solution was dried up, and then dissolved into $\mathrm{HBr}$. This was dried up by heating once more, and then dissolved into $1 \mathrm{M} \mathrm{HBr}$ again. On the anion exchange resin in $1 \mathrm{M} \mathrm{HBr}$, $\mathrm{Pd}$ was strongly adsorbed while organic substances passed through freely. Finally, Pd was collected in $0.5 \mathrm{M} \mathrm{HNO}_{3}$.

The solutions of purified $\mathrm{Pd}\left(5 \mathrm{ppm}\right.$ in $0.3 \mathrm{M} \mathrm{HNO}_{3}$ ) were analyzed on a Neptune (Thermo Fisher) multiplecollector inductively coupled plasma mass spectrometer (MC-ICPMS) at the "Pole Spectrometrie Ocean" (PSO) of Brest. Isotopes ${ }^{105} \mathrm{Pd},{ }^{106} \mathrm{Pd},{ }^{108} \mathrm{Pd}$, and ${ }^{110} \mathrm{Pd}$ were analyzed on Faraday collectors. The solutions were spiked with a Ag monoelemental solution (PlasmaCal, SCP Science, Canada), lot \#SC 7332640 with a purity of $99.999 \%$, for internal mass discrimination correction. ${ }^{111} \mathrm{Cd}$ and ${ }^{112} \mathrm{Cd}$ peaks were recorded to account for contributions of ${ }^{108} \mathrm{Cd}$ and ${ }^{110} \mathrm{Cd}$ on ${ }^{108} \mathrm{Pd}$ and ${ }^{110} \mathrm{Pd}$ signals respectively. The instrumental background was corrected for by measuring on peak zeros signals.

\section{Computational details}

The orbital geometries and vibrational frequencies of aqueous Pd(II) species were calculated by using the density functional theory (DFT) as implemented by the Gaussian03 code [18]. The DFT method employed here is a hybrid density functional consisting of Becke's [19] three-parameter non-local hybrid exchange potential (B3) with Lee-Yangand Parr (LYP) [20] non-local functionals. Similar to an $a b$ initio study on aqueous Pd(II) chlorides [21], we selected the basis sets. The $6-311+\mathrm{G}^{* *}$ basis set (all-electron basis set) was chosen for $\mathrm{H}, \mathrm{O}$, and $\mathrm{Cl}$. An effective-core potential (ECP) basis set, CEP-121G [22-24], was chosen for Pd. For the solvation effect, CPCM continuum solvation method (CPCM: conductor-like polarizable continuum model) was used.
As for the mass-independent isotope effect, the contribution of the nuclear volume was estimated by the numerical multiconfigurational Dirac-Coulomb Hartree-Fock (MCDCHF) method, which was implemented in the fourcomponent relativistic atomic program package GRASP2K [25]. Calculations of the electronic structure of $\operatorname{Pd}^{0}\left([\mathrm{Kr}] 4 d^{9} 4 s^{1}\right)$ and $\mathrm{Pd}^{2+}\left([\mathrm{Kr}] 4 d^{8}\right)$ were performed.

\section{Results and discussion}

Chemical species of $\mathrm{Pd}(\mathrm{II})$ in $\mathrm{HCl}$ media considered here are $\mathrm{Pd}^{2+}, \mathrm{PdCl}^{+}, \mathrm{PdCl}_{2}, \mathrm{PdCl}_{3}{ }^{-}$, and $\mathrm{PdCl}_{4}{ }^{2-}$, which are related through the following reactions,

$$
\begin{aligned}
& \mathrm{Pd}^{2+}+\mathrm{Cl}^{-} \rightleftarrows \mathrm{PdCl}^{+} \\
& \mathrm{PdCl}^{+}+\mathrm{Cl}^{-} \rightleftarrows \mathrm{PdCl}_{2} \\
& \mathrm{PdCl}_{2}+\mathrm{Cl}^{-} \rightleftarrows \mathrm{PdCl}_{3}{ }^{-} \\
& \mathrm{PdCl}_{3}{ }^{-}+\mathrm{Cl}^{-} \rightleftarrows \mathrm{PdCl}_{4}{ }^{2-}
\end{aligned}
$$

The apparent stability constants of equilibria 1 to 4 have been summarized in a literature [26]. Fig. 1 shows the mole fractions of Pd species estimated by using the reported stability constants at $[\mathrm{HCl}]<0.1 \mathrm{M}$.

The anionic species are easily formed in $\mathrm{HCl}$ system. The fractions of $\mathrm{Pd}(\mathrm{II})$ species are significantly switched in this region. The anionic species are predominant in our experimental acidity region $1.0-6.0 \mathrm{M} \mathrm{HCl}$.

A neutral ligand DC18C6 precedes ion association extraction, and hence the extraction reaction of $\mathrm{Pd}(\mathrm{II})$ may be written as,

$$
\mathrm{Pd}^{2+}+2 \mathrm{Cl}^{-}+L \rightleftarrows \mathrm{PdLCl}_{2}
$$

where L stands for DC18C6. The distribution ratio,

$$
D=\Sigma[\operatorname{Pd}(\mathrm{II})]_{\mathrm{org}} / \Sigma[\mathrm{Pd}(\mathrm{II})]_{\mathrm{aq}}
$$

where subscripts org and aq mean the organic and aqueous phases, respectively, is shown in Fig. 2. The distribution ratio once increased then decreased. The decrease of $D$ suggests a complaxation of crown ether with $\mathrm{H}_{3} \mathrm{O}^{+}[27,28]$, which may have depressed the extraction of Pd(II).

The isotope separation factor $\alpha_{\mathrm{m}}$, between the aqueous and the organic phases, is defined as,

$$
\alpha_{\mathrm{m}}=\left(\left[{ }^{m} \mathrm{Pd}\right] /\left[{ }^{106} \mathrm{Pd}\right]\right)_{\text {org }} /\left(\left[{ }^{m} \mathrm{Pd}\right] /\left[{ }^{106} \mathrm{Pd}\right]\right)_{\mathrm{aq}}
$$

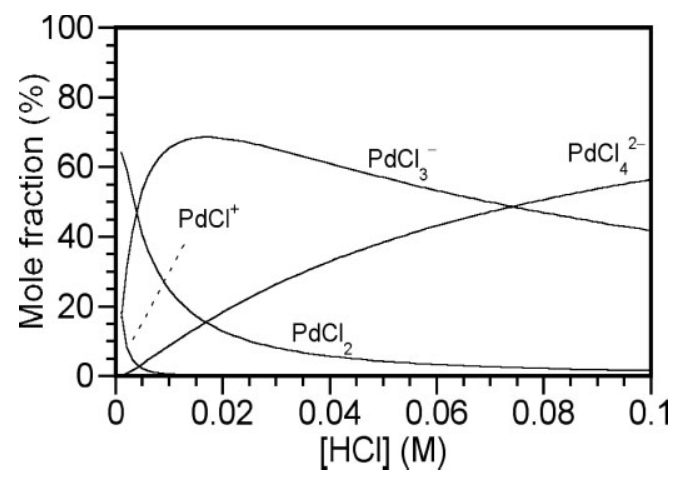

Fig. 1. Formations of the $\mathrm{Pd}(\mathrm{II})$ species in $\mathrm{HCl}$ solutions. The mole fractions were calculated from the reported stability constants (apparent) [26]. 


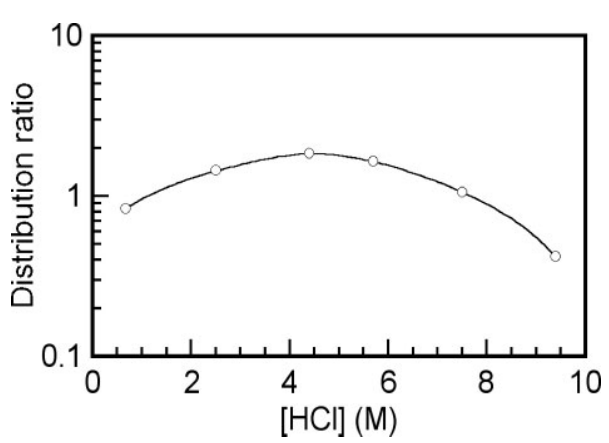

Fig. 2. Distribution ratio of $\mathrm{Pd}(\mathrm{II})$ as a function of $[\mathrm{HCl}]$.

Table 1. Isotope fractionation of palladium () \%०.

\begin{tabular}{lcrr}
\hline$[\mathrm{HCl}](\mathrm{M})$ & \multicolumn{1}{c}{$\delta^{105} \mathrm{Pd}$} & \multicolumn{1}{c}{$\delta^{108} \mathrm{Pd}$} & \multicolumn{1}{c}{$\delta^{110} \mathrm{Pd}$} \\
\hline 2.0 & $-0.24 \pm 0.01$ & $0.88 \pm 0.03$ & $1.60 \pm 0.04$ \\
5.3 & $1.48 \pm 0.35$ & $-0.43 \pm 0.53$ & $-0.86 \pm 0.61$ \\
7.0 & $0.72 \pm 0.04$ & $-1.22 \pm 0.05$ & $-2.53 \pm 0.16$ \\
\hline
\end{tabular}

The $2 \sigma$ uncertainties of $\delta^{\mathrm{m}} \mathrm{Pd}$ are shown. In our isotopic analysis, uncertainty of reproducibility is certified to be less than $\sim 0.6 \%$ o (e.g., $[\mathrm{HCl}]=5.3 \mathrm{M}$ case $)$

where the superscript $m$ indicates the mass of one particular isotope $(m=105,108$, or 110$) .\left(\left[{ }^{m} \mathrm{Pd}\right] /\left[{ }^{106} \mathrm{Pd}\right]\right)_{\text {org }}$ and $\left(\left[{ }^{m} \mathrm{Pd}\right] /\left[{ }^{106} \mathrm{Pd}\right]\right)_{\mathrm{aq}}$ are the isotopic ratios of ${ }^{m} \mathrm{Pd}$ relative to ${ }^{106} \mathrm{Pd}$ found in the organic and aqueous phases, respectively. In the present paper, we use $\delta$ notation, for which $\delta^{m} \mathrm{Pd}$ is defined as,

$$
\delta^{m} \mathrm{Pd}=\left(\alpha_{\mathrm{m}}-1\right) \times 1000
$$

Since $\alpha_{\mathrm{m}}$ is close to one, $\alpha_{\mathrm{m}}-1$ is approximately equal to $\ln \alpha_{\mathrm{m}}$. Theoretically, legarithms of reduced partition function ratios (RPFRs) are used to derive $\ln \alpha_{\mathrm{m}}$ [6].

The $\delta^{m} \mathrm{Pd}$ values obtained are shown in Table 1. The errors on isotope fractionation factor are mainly due to mass spectrometry [12]. Two standard deviation of the repeated measurements $(2 \sigma)$ is shown together. The classic theory of chemical isotope fractionation is based on the mass-dependent isotope effect via the isotopic difference in vibrational energies of isotopologues [5,6]. The isotope enrichment factor is proportional to $\delta \mathrm{m} / \mathrm{mm}^{\prime}$, where $\delta m$ means the isotopic mass difference of masses $m$ and $m^{\prime}$ of two isotopes (prime represents the light isotope). In the present study, mass-dependence of isotope fractionation can be assessed by fitting $\delta^{m} \mathrm{Pd}$ on a linear function of (106- $m) /(m \times 106)$. At all acidities, even atomic mass isotopes $\left(\delta^{106} \mathrm{Pd}=0, \delta^{108} \mathrm{Pd}\right.$, and $\left.\delta^{110} \mathrm{Pd}\right)$ showed a good relation with $(106-m) /(m \times 106)$, while $\delta^{105} \mathrm{Pd}$ broke the relationshop. $\delta^{105} \mathrm{Pd}$ was found to be larger than the value expected from $\delta^{m} \mathrm{Pd}$ 's of the even atomic mass isotopes. This trend is graphically shown in Fig. 2a with the $\delta^{m} \mathrm{Pd}$ data at $[\mathrm{HCl}]=5.3 \mathrm{M}$. For comparison, isotopic difference in nuclear charge radius, $\delta\left\langle r^{2}\right\rangle$ is shown in Fig. 2b. A similar trend can be seen.

The conventional mass-dependent theory has been expanded by adding the nuclear field shift effect [8],

$$
\ln \alpha=\frac{h c}{k T} v_{\mathrm{fs}} a+\frac{1}{24}\left(\frac{\hbar}{k T}\right)^{2} \frac{\delta m}{m m^{\prime}} b
$$

where $v_{\mathrm{fs}}$ is the nuclear field shift, $a$ the nuclear field shift scaling factor, and $b$ the scaling factor for the conventional mass effect. $h$ is the Plank constant, $c$ the light velocity, $k$ the Boltzmann constant, and $T$ temperature. The nuclear field shift effect is recognized as the origin of the massindependent isotope fractionation in chemical exchange reactions [10]. The nuclear field shift is an isotope shift in orbital electrons [29]. This results from the isotopic difference in the nuclear size and shape. Different isotopes have the same number of protons, but they do not have the same distribution of protons in space. The nuclear charge distribution, which is usually represented as the mean-square charge radius $\left\langle r^{2}\right\rangle$, is affected by the number of neutrons in the nucleus. The nuclear charge distribution gives an electric field, and its isotopic difference shifts the atomic energy levels, also displacing the electronic molecular states. The nuclear field shift is not mass-dependent but is strongly related to the neutron configuration of nuclear structure. The nuclear field shift $v_{\mathrm{fs}}$ is proportional to the isotopic difference in the mean-square charge radius, $\delta\left\langle r^{2}\right\rangle[29]$.

Recent quantum chemical studies have adopted finite nucleus models into $a b$ initio methods [14,30,31]. In the present study, the total electronic energies at the ground states of $\mathrm{Pd}^{0}\left([\mathrm{Kr}] 3 d^{9} 4 s^{1}\right)$ and $\mathrm{Pd}^{2+}\left([\mathrm{Kr}] 3 d^{8}\right)$ were calculated for different isotopes with different nuclear charge radii. The most stable energy states of $[\mathrm{Kr}] 3 d^{x} 4 s^{y}$ calculated were used. The root mean square radii $\left(\left\langle r^{2}\right\rangle^{1 / 2}\right)$ reported in the literature [15] were used in the calculation. The calculation results are shown in Table 2 in atomic units (a.u.). The nuclear field shift effect is attributable to the probability density of electrons at nucleus, and hence, the drastic change in the electron configuration should cause a larger effect. As a drastic case, the nuclear field shift effect in $\mathrm{Pd}^{0}-\mathrm{Pd}^{2+}$ redox reaction was estimated. It should be noted that our experimental system is a ligand exchange system of $\mathrm{Pd}(\mathrm{II})$

\begin{tabular}{|c|c|c|c|c|}
\hline & $\begin{array}{c}\left\langle r^{2}\right\rangle^{1 / 2} \\
(\mathrm{fm})\end{array}$ & $\begin{array}{c}\mathrm{Pd}^{2+} \text { total } \\
\text { energy (a.u.) }\end{array}$ & $\begin{array}{c}\mathrm{Pd}^{0} \text { total } \\
\text { energy (a.u.) }\end{array}$ & $\begin{array}{l}\text { NFS effect }^{a} \\
\left(\times 10^{-3}\right)\end{array}$ \\
\hline${ }^{105} \mathrm{Pd}$ & $4.514 \pm 0.002$ & -5043.517660946 & -5044.404068138 & -0.052 \\
\hline${ }^{106} \mathrm{Pd}$ & $4.531 \pm 0.003$ & -5043.516977647 & -5044.403384790 & 0.000 \\
\hline${ }^{108} \mathrm{Pd}$ & $4.556 \pm 0.003$ & -5043.515968725 & -5044.402375794 & 0.078 \\
\hline${ }^{110} \mathrm{Pd}$ & $4.578 \pm 0.002$ & -5043.515076867 & -5044.401483872 & 0.146 \\
\hline
\end{tabular}

Table 2. Total energy of $\mathrm{Pd}(\mathrm{II})$ and $\mathrm{Pd}^{0}$ for $\mathrm{Pd}$ isotopes.

a: Nuclear field shift effect, $\left\{\delta E\left(\mathrm{Pd}^{0}\right)-\delta E\left(\mathrm{Pd}^{2+}\right)\right\} / k T, T=298.2 \mathrm{~K}$. The uncertainty was estimated in the seme manner with the literature [30], and was $\sim 2 \%$ of each NFS effect. 

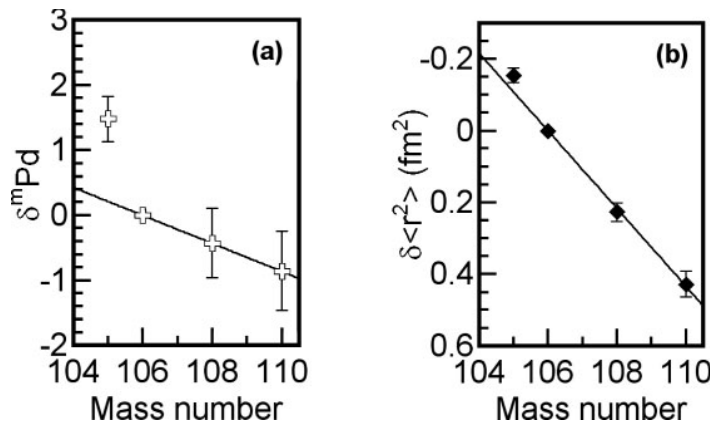

Fig. 3. $\delta^{\mathrm{m}} \mathrm{Pd}$ and $\delta\left\langle r^{2}\right\rangle$ as functions of mass number. (a) $\delta^{\mathrm{m}} \mathrm{Pd}$ at $[\mathrm{HCl}]=5.3 \mathrm{M}$. (b) Isotopic difference in nuclear charge radius, $\delta\left\langle r^{2}\right\rangle=$ $\delta\left\langle r^{2}\right\rangle\left({ }^{\mathrm{m}} \mathrm{Pd}\right)-\delta\left\langle r^{2}\right\rangle\left({ }^{106} \mathrm{Pd}\right)$. The $\left\langle r^{2}\right\rangle$ values were reproduced from [15].

complexes, that is, $\mathrm{Pd}^{2+}, \mathrm{PdCl}^{+}, \mathrm{PdCl}_{2}, \mathrm{PdCl}_{3-}, \mathrm{PdCl}_{4}{ }^{2-}$, and $\mathrm{PdLCl}_{2}$.

From the data shown in Tables 1 and 2, in the most drastic case, the contribution of nuclear field shift effect to $\delta^{m} \mathrm{Pd}$ is expected to be $\sim 10 \%$. Theoretically and experimentally, the nuclear field shift effect as the mass-independent isotope fractionation is possible, nevertheless, the contribution of the conventional mass effect is larger in the present study.

We estimated the magnitude of the mass-dependent isotope fractionation. Isotope exchange reactions in reactions 1-4 have taken place in the present study. The intramolecular vibrations of the $\mathrm{Pd}(\mathrm{II})$ complexes $\left(\mathrm{Pd}^{2+}, \mathrm{PdCl}^{+}, \mathrm{PdCl}_{2}\right.$, $\mathrm{PdCl}_{3}{ }^{-}$, and $\mathrm{PdCl}_{4}{ }^{2-}$ ) in the aqueous phase and those of $\mathrm{PdLCl}_{2}$ in the organic phase should cause the mass effect. It is difficult to model Pd-crown complex in $a b$ initio calculation, but to model aqueous Pd complexes would be possible.

The structural studies of hydrated $\mathrm{Pd}^{2+}$ and aqueous palladium chlorides have been intensely performed [21,32-41]. In order to evaluate the respective strength of mass-dependent effects, we performed some quantum chemical analysis calculations of the vibrational energies of the aqueous $\mathrm{Pd}$ (II) species. It is well known that the core structure of $\mathrm{Pd}$ (II) complex has the square-planar structure via the hybrid orbital $d s p^{2}$. The hydrated $\mathrm{Pd}^{2+}$ with the first coordination sphere is generally expressed as $\mathrm{Pd}\left(\mathrm{H}_{2} \mathrm{O}\right)_{4}{ }^{2+}$. For this equatorial plane, two water molecules are arranged at the axial orientation. The shell including the first coordination sphere and the two water molecules called "meso-shell." The Pd$\mathrm{O}$ bond length for water molecules at the axial positions is longer than that at the equatorial postitions. The two waters at the axial position are stabilized by water molecules in second coordination sphere [39]. Initially, the calculation of this aqua complex was examined. The Pd-O bond distance calculated is shown in Table 3. The literature values are shown together. We performed structural analysis of $\mathrm{Pd}\left(\mathrm{H}_{2} \mathrm{O}\right)_{4}{ }^{2+}$ and $\mathrm{Pd}\left(\mathrm{H}_{2} \mathrm{O}\right)_{14}{ }^{2+}$. Our calculation results are consistent with other calculation methods [21,36-41]. Setting water molecules in the meso-shell and the second hydration sphere shortened the $\mathrm{Pd}-\mathrm{O}$ bond distance $0.011 \AA$ in the first coordination sphere. The difference was also reproducible by using CPCM method for $\mathrm{Pd}\left(\mathrm{H}_{2} \mathrm{O}\right)_{4}{ }^{2+}$.

For aqueous palladium chlorides, structural studies on an anionic species $\mathrm{PdCl}_{4}{ }^{2-}$ have been commonly performed [21,32-35]. The Pd-O bond distance calculated is shown in Table 3. The literature values are shown together. We performed structural analysis of $\mathrm{PdCl}_{4}{ }^{2-}$ and
Table 3. Bond distances determined for hydrated $\mathrm{Pd}^{2+}$.

\begin{tabular}{lcc}
\hline Method $^{a}$ & Bond $^{a}, \mathrm{Pd}-\mathrm{O}(\AA)$ & Reference \\
\hline DFT & $2.062(4)$ & This work \\
DFT $^{c}$ & $2.050(4)$ & This work \\
DFT & $2.051(4)$ & This work \\
& $2.959(2)$ & \\
& $4.249(8)$ & {$[21]$} \\
DFT & $2.052-2.065(4)$ & {$[37]$} \\
MD & $2.019(4)$ & \\
& $2.780(2)$ & {$[38]$} \\
QM/MM MD & $2.07(4)$ & {$[39]$} \\
& $2.66(1)$ & \\
QMCF MD & $2.05(4)$ & {$[40,41]$} \\
& $2.71(2)$ & \\
CP MD & $4.4(8)$ & {$[36]$} \\
& $2.04(4)$ & {$[39]$} \\
EXAFS & $3.5(1.1)$ & \\
EXAFS & $4.02(10.3)$ & \\
& $2.001(4)$ & $2.5(2)$ \\
\hline
\end{tabular}

a: DFT (density functional theory), MD (molecular dynamics), $\mathrm{QM} / \mathrm{MM}$ (quantum mechanics/molecular mechanics), QMCF (quantum mechanical charge filed), CP (Car-Perrinello), EXAFS (extended $\mathrm{X}$-ray absorption fine structure);

b: Numbers of bonds are shown in parentheses;

c: CPCM was used.

$\left[\mathrm{PdCl}_{4}\left(\mathrm{H}_{2} \mathrm{O}\right)_{10}\right]^{2-}$, in which four water molecules of the first coordination sphere of $\mathrm{Pd}\left(\mathrm{H}_{2} \mathrm{O}\right)_{14}{ }^{2+}$ were substituted by $\mathrm{Cl}^{-}$to form $\left[\mathrm{PdCl}_{4}\left(\mathrm{H}_{2} \mathrm{O}\right)_{10}\right]^{2-}$. The $\mathrm{Pd}-\mathrm{Cl}$ bond distances showed similar values. Setting water molecules around $\mathrm{PdCl}_{4}{ }^{2-}$ shortened the $\mathrm{Pd}-\mathrm{Cl}$ bond distance, which came closer to that experimentally determined $[32,33]$. An experimental study suggested that two water molecules exist in the meso-shell [33], while a theoretical study resulted in no waters in the meso-shell but eight waters in the second coordination sphere [35]. In our calculation, if we set two waters in the meso-shell, their Pd-O distance increased to be close to that of eight water molecules in the second coordination sphere.

The structures of $\mathrm{PdCl}_{n}\left(\mathrm{H}_{2} \mathrm{O}\right)_{4-n}^{2-n}$ and $\mathrm{PdCl}_{n}\left(\mathrm{H}_{2} \mathrm{O}\right)_{14-n}^{2-n}$ ( $n=0,1,2,3$, or 4 ) were optimized and then intramolecular frequencies of these species were calculated in order to evaluate $\delta^{m} \mathrm{Pd}$. The isotope enrichment factor due to the intramolecular vibrations can be evaluated from the reduced partition function ratio (RPFR) [6], $\left(s / s^{\prime}\right) f$,

$$
\begin{aligned}
& \ln \left(s / s^{\prime}\right) f=\Sigma\left[\ln b\left(u_{i}^{\prime}\right)-\ln b\left(u_{i}\right)\right] \\
& \ln b\left(u_{i}\right)=-\ln u_{i}+u_{i} / 2+\ln \left(1-e^{-u i}\right) \\
& u_{i}=h v_{i} / k T
\end{aligned}
$$

where $v$ means vibrational frequency. The subscript $i$ stands for the $i$ th molecular vibrational level with primed variables referring to the light isotopologue. The isotope enrichment factor due to the molecular vibration can be evaluated from the frequencies $(v)$ summed over all the different modes. The RPFRs obtained for the isotope pair ${ }^{106} \mathrm{Pd}-{ }^{108} \mathrm{Pd}$ at $298 \mathrm{~K}$ were shown in Table 5 . The RPFRs showed magnitudes in 
Table 4. Bond distances determined for $\mathrm{PdCl}_{4}{ }^{2-}$ and $\left[\mathrm{PdCl}_{4}\left(\mathrm{H}_{2} \mathrm{O}\right)_{10}\right]^{2-}$.

\begin{tabular}{|c|c|c|c|}
\hline Method $^{a}$ & $\begin{array}{c}\text { Bond, } \\
\text { Pd-O (̊) }\end{array}$ & $\begin{array}{l}\text { Bond, } \\
\text { Pd-Cl }(\AA)\end{array}$ & Reference \\
\hline DFT & & $2.425(4)$ & This work \\
\hline DFT & $\begin{array}{l}4.389(2) \\
4.419(8)\end{array}$ & $2.396(4)$ & This work \\
\hline DFT & & $2.420(4)$ & [21] \\
\hline DFT & & $2.329(4)$ & [34] \\
\hline MM MD & & $2.307(4)$ & [34] \\
\hline QM/MM MD & $3.62(8)$ & $-{ }^{b}$ & {$[35]$} \\
\hline LAXS & & $2.315(4)$ & [32] \\
\hline LAXS & $2.77(2)$ & $2.315(4)$ & [33] \\
\hline
\end{tabular}

a: LAXS (large angle X-ray scattering);

b: Not reported.

Table 5. Logarithm of the reduced partition function, $\ln \left(s / s^{\prime}\right) f$, for isotope pair ${ }^{106} \mathrm{Pd}-{ }^{108} \mathrm{Pd}$ at $298 \mathrm{~K}$.

$10^{3} \ln \left(\mathrm{s} / \mathrm{s}^{\prime}\right) f$

\begin{tabular}{lc}
\hline $\mathrm{Pd}\left(\mathrm{H}_{2} \mathrm{O}\right)_{4}{ }^{2+}$ & $2.54,2.52^{a}$ \\
$\mathrm{PdCl}\left(\mathrm{H}_{2} \mathrm{O}\right)_{3}{ }^{+}$ & 2.30 \\
$\mathrm{PdCl}_{2}\left(\mathrm{H}_{2} \mathrm{O}\right)_{2}$ & 2.07 \\
$\mathrm{PdCl}_{3}\left(\mathrm{H}_{2} \mathrm{O}\right)^{-}$ & 1.76 \\
$\mathrm{PdCl}_{4}{ }^{-}$ & 1.28 \\
$\left.\mathrm{Pd}_{2} \mathrm{O}\right)_{14}{ }^{2+}$ & 2.70 \\
$\left.\mathrm{PdCl}_{2} \mathrm{H}_{2} \mathrm{O}\right)_{13}{ }^{+}$ & 2.50 \\
$\mathrm{PdCl}_{2}\left(\mathrm{H}_{2} \mathrm{O}\right)_{12}$ & 2.24 \\
$\mathrm{PdCl}_{3}\left(\mathrm{H}_{2} \mathrm{O}\right)_{11}{ }^{-}$ & 1.94 \\
$\mathrm{PdCl}_{3}\left(\mathrm{H}_{2} \mathrm{O}\right)_{10}{ }^{2-}$ & 1.64 \\
\hline
\end{tabular}

a: CPCM was used.

the range $1.28 \sim 2.70 \%$. There are three prominent features: 1) Substitution of $\mathrm{H}_{2} \mathrm{O}$ by $\mathrm{Cl}^{-}$decreases the RPFR; and, 2) Setting the second hydration sphere increases the RPFR, and 3) Using CPCM shortens the Pd-O bond length but does not change RPFR so much. The third feature has also been pointed out for aquo ion of $\mathrm{Sr}^{2+}$ [42]. Though the structure of the Pd-crown complex is not clear, a similar magnitude of the RPFR may be expected. According to the data in Table 5, the maximum difference in the RPFRs is $\ln \left(s / s^{\prime}\right) f\left[\mathrm{Pd}\left(\mathrm{H}_{2} \mathrm{O}\right)_{14}{ }^{2+}\right]-\ln \left(s / s^{\prime}\right) f\left[\mathrm{PdCl}_{4}{ }^{2-}\right]=1.42 \%$. This magnitude covers $\delta^{108} \mathrm{Pd}$ 's shown in Table 1 , and this suggests that isotope fractionation of Pd could be explained by the intramolecular vibration. If the RPFR of Pd-Crown complex is determined, $\delta^{m} \mathrm{Pd}$ via intramolecular vibrations can be estimated by using mole fractions of aqueous and organic $\mathrm{Pd}$ species $\left(\mathrm{Pd}^{2+}, \mathrm{PdCl}^{+}, \mathrm{PdCl}_{2}, \mathrm{PdCl}_{3}{ }^{-}, \mathrm{PdCl}_{4}{ }^{2-}\right.$, and $\mathrm{Pd}-$ Crown complex) and their RPFRs as we have reported on first-row transition metals $[43,44]$.

\section{Conclusions}

Palladium isotopes were fractionated in the chemical exchange reaction with DC18C6. $\delta^{m}$ Pd observed resulted from the intramolecular vibrations and the nuclear field shift effect. A maximum contribution of the nuclear field shift effect was estimated to be $\sim 10 \%$ of $\delta^{m} \mathrm{Pd}$ by quantum chemical calculations. The reduced partition function ratios
(RPFRs) of $\mathrm{PdCl}_{n}\left(\mathrm{H}_{2} \mathrm{O}\right)_{4-n}{ }^{2-n}$ and $\mathrm{PdCl}_{n}\left(\mathrm{H}_{2} \mathrm{O}\right)_{14-n}{ }^{2-n}$ were obtained by quantum chemical calculations. The magnitude of RPFRs agreed with that of $\delta^{m} \mathrm{Pd}$ experimentally obtained.

Acknowledgment. TF thanks Roy Jacobus for his help in improving the English of this paper. AA is thankful to the Conseil Régional de Bretagne for its financial support. FM acknowledges support from NASA LASER \#NNX09AM64G.

\section{References}

1. Hutchison, C. A., Stewart, D. W., Urey, H. C.: The concentration of $\mathrm{C}^{13}$. J. Chem. Phys. 8, 532 (1940).

2. Urey, H. C., Huffman, J. R., Thode, H. G., Fox, M.: Concentration of $\mathrm{N}^{15}$ by chemical methods. J. Chem. Phys. 5, 856 (1937).

3. Stewart, D. W., Cohen, K.: The further concentration of $\mathrm{S}^{34}$. J. Chem. Phys. 8, 904 (1940).

4. Bigeleisen, J.: History and theory of uranium isotope enrichment by chemical exchange. Bull. Res. Lab. Nucl. React. 16(Special Issue 1), 3 (1992).

5. Urey, H. C.: The thermodynamic properties of isotopic substances. J. Chem. Soc. 562 (1947).

6. Bigeleisen, J., Mayer, M. G.: Calculation of equilibrium constants for isotopic exchange reactions. J. Chem. Phys. 15, 261 (1947).

7. Nishizawa, K., Nakamura, K., Yamamoto, T., Masuda, T.: Separation of strontium and barium isotopes using a crown-ether. Different behaviors of odd mass and even mass isotopes. Solvent Extr. Ion Exch. 12, 1073 (1994).

8. Bigeleisen, J.: Nuclear size and shape effects in chemical reactions. Isotope chemistry of the heavy elements. J. Am. Chem. Soc. 118, 3676 (1996).

9. Nomura, M., Higuchi, N., Fujii, Y.: Mass dependence of uranium isotope effects in the U(IV)-U(VI) exchange reaction. J. Am. Chem. Soc. 118, 9127 (1996).

10. Fujii, T., Moynier, F., Albarède, F.: The nuclear field shift effect in chemical exchange reactions. Chem. Geol. 267,139 (2009).

11. Fujii, T., Moynier, F., Albarède, F.: Nuclear field vs nucleosynthetic effects as cause of isotopic anomalies in the early solar system. Earth Planet. Sci. Lett. 247, 1 (2006).

12. Fujii, T., Moynier, F., Telouk, P., Albarède, F.: Mass-independent isotope fractionation of molybdenum and ruthenium and the origin of isotopic anomalies in Murchison. Astrophys. J. 647,1506 (2006).

13. Bergquist, B. A., Blum, J. D.: Mass-dependent and -independent fraction of $\mathrm{Hg}$ isotopes by photoreduction in aquatic systems. Science 318, 417 (2007).

14. Schauble, E. A.: Role of nuclear volume in driving equilibrium stable isotope fractionation of mercury, thallium, and other very heavy elements, Geochim. Cosmochim. Acta 71, 2189 (2007).

15. Fricke, G., Heilig, K.: Nuclear Charge Radii (Landolt-Bornstein Numerical Data and Functional Relationships in Science and Technology - New Series). (Schopper, H., ed.) Springer, Berlin (2004).

16. Jepson, B. E., DeWitt, R.: Separation of calcium isotopes with macrocyclic polyether calcium complex. J. Inorg. Nucl. Chem. 38, 1175 (1976).

17. Tsuvadze, A. Yu., Zhilov, V. I., Demin, S. V.: Isotope separation with macrocyclic polyethers. Russ. J. Coord. Chem. 22, 229 (1996).

18. Frisch, M. J., Trucks, G. W., Schlegel, H. B., Scuseria, G. E., Robb, M. A., Cheeseman, J. R., Montgomery Jr., J. A., Vreven, T., Kudin, K. N., Burant, J. C., Millam, J. M., Iyengar, S. S., Tomasi, J., Barone, V., Mennucci, B., Cossi, M., Scalmani, G., Rega, N., Petersson, G. A., Nakatsuji, H., Hada, M., Ehara, M., Toyota, K., Fukuda, R., Hasegawa, J., Ishida, M., Nakajima, T., Honda, Y., Kitao, O., Nakai, H., Klene, M., Li, X., Knox, J. E., Hratchian, H. P., Cross, J. B., Adamo, C., Jaramillo, J., Gomperts, R., Stratmann, R. E., Yazyev, O., Austin, A. J., Cammi, R., Pomelli, C., Ochterski, J. W., Ayala, P. Y., Morokuma, K., Voth, G. A., Salvador, P., Dannenberg, J. J., Zakrzewski, V. G., Dapprich, S., Daniels, A. D., Strain, M. C., Farkas, O., Malick, D. K., Rabuck, A. D., Raghavachari, K., Foresman, J. B., Ortiz, J. V., Cui, Q., Baboul, A. G., Clifford, S., Cioslowski, J., Stefanov, B. B., Liu, G., Liashenko, A., Piskorz, P., Komaromi, I., Martin, R. L., Fox, D. J., Keith, T., Al- 
Laham, M. A., Peng, C. Y., Nanayakkara, A., Challacombe, M., Gill, P. M. W., Johnson, B., Chen, W., Wong, M. W., Gonzalez, C., Pople, J. A.: Gaussian 03, Revision, B.05, Gaussian, Inc.: Pittsburgh PA, 2003.

19. Becke, A. D.: Density-functional thermochemistry. 3. The role of exact exchange. J. Chem. Phys. 98, 5648 (1993).

20. Lee, C. T., Yang, W. T., Parr, R. G.: Development of the collesalvetti correlation-energy formula into a functional of the electron-density. Phys. Rev. B 37, 785 (1988).

21. Boily, J. F., Seward, T. M.: Palladium(II) chloride complexation: Spectrophotometric investigation in aqueous solutions from 5 to $125^{\circ} \mathrm{C}$ and theoretical insight into $\mathrm{Pd}-\mathrm{Cl}$ and $\mathrm{Pd}-\mathrm{OH}_{2}$ interactions. Geochim. Cosmochim. Acta 69, 3773 (2005).

22. Stevens, W. J., Basch, H., Krauss, J.: Compact effective potentials and efficient shared-exponent basis sets for the first- and secondrow atoms. J. Chem. Phys. 81, 6026 (1984).

23. Stevens, W. J., Krauss, J., Basch, H., Jasien, P. G.: Relativistic compact effective potentials and efficient, shared-exponent basissets for the 3rd-row, 4th-row, and 5th-row atoms. Can. J. Chem. 70, 612 (1992).

24. Cundari, T. R., Stevens, W. J.: Effective core potential methods for the lanthanides. J. Chem. Phys. 98, 5555 (1993).

25. Jönsson, P., He, X., Fischer, C. F., Grant, I. P.: The grasp2K relativistic atomic structure package. Comput. Phys. Commun. 177, 597 (2007).

26. Kragten, J.: An evaluation of the stability constants of the chlorocomplexes of palladium(II). Talanta 27, 375 (1980).

27. Izatt, R. M., Christen, J. J., Haymore, B. L.: Stable $\mathrm{OH}_{3}{ }^{+}$-cyclic polyether complex characterized by infrared spectroscopy. J. Chem. Soc. Chem. Commun. 23, 1308 (1972)

28. Junk, P. C.: Structural aspects of oxonium ion/crown ether complexes. Rev. Inorg. Chem. 21, 93 (2001).

29. King, W. H.: Isotope Shifts in Atomic Spectra. Plenum Press, New York (1984)

30. Abe, M., Suzuki, T., Fuji, Y., Hada, M.: An ab initio study based on a finite nucleus model for isotope fractionation in the U(III)-(IV) exchange reaction system. J. Chem. Phys. 128, 144309 (2008).

31. Abe, M., Suzuki, T., Fujii, Y., Hada, M., Hirao, K.: An ab initio molecular orbital study of the nuclear volume effects in uranium isotope fractionations. J. Chem. Phys. 129, 164309 (2008).

32. Caminiti, R., Sadun, C., Basanisi, M., Carbone, M.: X-ray scattering studies of palladium(II) and platinum(II) aqueous solutions. J. Mol. Liq. 70, 55 (1996).
33. Caminiti, R., Carbone, M., Sadun. C.: Palladium(II) and platinum(II) aqueous solutions. Evidence for the solvation of the $\left[\mathrm{PdCl}_{4}\right]^{2-}$ and $\left[\mathrm{PtCl}_{4}\right]^{2-}$ ions. J. Mol. Liq. 75, 149 (1998).

34. Lienke, A., Klatt, G., Robinson, D. J., Koch, K. R., Naidoo, K. J.: Modeling platinum group metal complexes in aqueous solution. Inorg. Chem. 40, 2352 (2001).

35. Naidoo, K. J., Klatt, G., Koch, K. R., Robinson, D. J.: Geometric hydration shells for anionic platinum group metal chloro complexes. Inorg. Chem. 41, 1845 (2002).

36. Purans, J., Fourest, B., Cannes, C., Sladkov, V., David, F., Venault, L., Lecomte, M.: Structural investigation of Pd(II) in concentrated nitric and perchloric acid solutions by XAFS. J. Phys. Chem. B 109, 11074 (2005).

37. Torrico, F., Poppalardo, R. R., Marcos, E. S., Martínex, J. M.: Hydration structure and dynamic properties of the square planer $\mathrm{Pt}(\mathrm{II})$ aqua ion compared to the Pd(II) case. Theor. Chem. Acc. 115, 196 (2006).

38. Ali Shah, S. A., Hofer, T. S., Fatmi, M. Q., Randolf, B. R., Rode, B. M.: A QM/MM MD simulation study of hydrated $\mathrm{Pd}^{2+}$. Chem. Phys. Lett. 426, 301 (2007).

39. Hofer, T. S., Randolf, B. R., Ali Shah, S. A., Rode, B. M., Persson, I.: Structure and dynamics of the hydrated palladium(II) ion in aqueous solution A QMCF MD simulation and EXAFS spectroscopic study. Chem. Phys. Lett. 445, 193 (2007).

40. Beret, E. C., Poppalardo, R. R., Doltsinis, N. L., Marx, D., Marcos, E. S.: Aqueous $\mathrm{Pd}^{\mathrm{II}}$ and $\mathrm{Pt}^{\mathrm{II}}$. Anionic hydration revealed by Car-Perrinello Simulations. Chem. Phys. Chem. 9, 237 (2008).

41. Beret, E. C., Martínex, J. M., Poppalardo, R. R., Marcos, E. S., Doltsinis, N. L., Marx, D.: Explaining asymmetric solvation of $\mathrm{Pt}(\mathrm{II})$ vs. $\mathrm{Pd}(\mathrm{II})$ in aqueous solution revealed by ab initio molecular dynamics simulations. J. Chem. Teory Comput. 4, 2108, (2008),

42. Fujii, T., Fukutani, S., Yamana, H.: Isotope fractionation of strontium in a precipitation reaction of $\mathrm{SrO}_{2}$. J. Nucl. Sci. Technol. 6(Suppl.), 15 (2008).

43. Fujii, T., Moynier, F., Telouk, P., Albarède, F.: Isotope fractionation of iron(iii) in chemical exchange reactions using solvent extraction with crown ether. J. Phys. Chem. A 110, 11108 (2006).

44. Fujii, T., Moynier, F., Telouk, P., Abe, M.: Experimental and theoretical investigation of isotope fractionation of zinc between aqua, chloro, and macrocyclic complexes. J. Phys. Chem. A 114, 2543 (2010). 